\title{
Optimal learning strategies and their spontaneous use: The importance of task-appropriate processing
}

\author{
MARK A. McDANIEL and EDMUND M. KEARNEY \\ University of Notre Dame, Notre Dame, Indiana
}

\begin{abstract}
College students were given three verbal learning tasks to perform, with some subjects instructed to use a particular verbal or imaginal encoding strategy for all three tasks and other subjects not instructed to use any particular strategy. It was found that the relative effectiveness of the assigned encoding strategies varied as a function of the learning task. In addition, "uninstructed" subjects, for the most part, spontaneously employed strategies that produced recall comparable to that observed for subjects assigned the most effective strategy for a particular learning task. In Experiment 2, subjects were instructed to perform a different encoding strategy for each learning task. Subjects who were assigned the strategies in a "task-appropriate" fashion recalled more, in general, than subjects who were assigned the same strategies paired with the learning tasks in a haphazard fashion. Subjects not instructed to use a particular strategy again demonstrated relatively high recall and were found to vary processing across learning tasks. It was concluded that optimal learning for a range of tasks can require deployment of several semantic/elaborative strategies in a task-appropriate fashion. Furthermore, mature learners seem to spontaneously utilize semantic and imaginal strategies and do so task appropriately.
\end{abstract}

In recent years, there has been a great deal of interest in the processing and encoding strategies that support optimal retention of verbal material. Within this area, two general research thrusts can be identified: (1) identifying the type of processing that leads to optimal retention and (2) exploring learners' spontaneous use of these processing strategies (Pressley, Heisel, McCormick, \& Nakamura, 1982). The present paper addresses several issues encompassing both of these research areas.

One popular view stresses the idea that remembering is dependent on the degree to which an item is semantically processed (Craik \& Lockhart, 1972). Empirical work generally has supported this claim. College-age subjects instructed to perform a semantic processing task on a list of words demonstrate better retention than subjects instructed to perform a nonsemantic processing task (Craik \& Tulving, 1975; Jenkins, 1974; McDaniel \& Masson, 1977). McDaniel and Masson (1977) also reported that subjects not receiving instructions to perform a particular processing task remember as many

The results of these studies were reported in part at the American Psychological Association Meeting, Washington, DC, August 1982. Edmund Kearney is now at the Psychology Department at Loyola University. Comments from Gilles Einstein and Michael Pressley on an earlier version of this paper are gratefully acknowledged. Appreciation is extended to Deborah Smith and Paul Konstanty for assistance with Experiment 2. Reprint requests should be addressed to Mark A. McDaniel, Department of Psychology, University of Notre Dame, Notre Dame, Indiana 46556. (or more) items as do subjects instructed to perform semantic processing and more items than subjects instructed to perform nonsemantic processing. Recent studies investigating vocabulary learning have reported similar findings. Uninstructed subjects remember as many meanings as do subjects instructed to employ particular semantic encoding strategies (Pressley, Levin, Kuiper, Bryant, \& Michener, 1982), and, in some instances, uninstructed subjects perform as well as subjects taught to use the keyword method of learning, a highly effective mnemonic for vocabulary learning (McDaniel \& Pressley, in press). These results imply that mature learners employ relatively sophisticated learning strategies involving elaborative and/or semantic processing.

Nonetheless, not all of the available data support the conclusion that mature learners routinely use elaborative/ semantic processing strategies. For instance, half of Stoff and Eagle's (1971) uninstructed subjects reported learning an uncategorized word list by simply repeating the items to themselves. Furthermore, these subjects did not perform as well on a memory test as subjects instructed to use a semantic processing strategy. Similarly, in a study by Shaughriessy (1981), uninstructed subjects predominantly used a rote repetition rehearsal strategy, and subsequently performed worse on final free recall than subjects instructed to use an elaboration strategy. In Mazuryk and Lockhart (1974), learners used maintenance rehearsal (rote rehearsal) unless instructed to do otherwise. 
Thus, the extant findings do not support any straightforward conclusions regarding the efficacy of strategy use by mature learners. It could be that mature learners possess a variety of strategies (Battig, 1975), but for some reason employ semantic/elaborative strategies in some learning situations and rote rehearsal strategies in other situations. Another possibility, however, is that learners employ a single strategy that is differentially effective across different leaming materials (Hunt \& Einstein, 1981). For instance, adult learners might consistently use maintenance rehearsal, performing poorly in a learning situation in which maintenance rehearsal does not promote effective learning (e.g., a pairedassociate task-Pressley, 1982) but performing well in learning situations for which maintenance rehearsal is not inimical [e.g., long-term recall of a short list of items (Aldridge \& Crisp, 1982) or recall of a structured word list (Ambler \& Maples, 1977)]. Still a third possibility is that some learners may possess and deploy effective strategies across a wide variety of leaming tasks, whereas other learners may not possess effective learning strategies for even a handful of learning tasks (Pressley et al., 1982). If so, then differential performance for uninstructed subjects across studies might simply reflect a predominance of one type of learner or the other.

The following experiments were performed to explore the hypotheses outlined above. Memory performance and strategy utilization were assessed for subjects not instructed to use any particular processing strategy. Using a within-subjects design, three different learning situations typically employed in the literature were examined: paired-associate learning, structured list learning, and vocabulary learning. To provide a point of comparison for uninstructed leamers, three other groups of subjects were instructed with various encoding strategies requiring semantic/elaborative processing. This design enabled us to address the following issues. First, to what extent do mature learners spontaneously utilize rote rehearsal (or nonsemantic processing) rather than the more effective elaborative rehearsal (Craik \& Tulving, 1975 ) across a variety of learning situations? Second, do mature learners tend to employ one strategy across all tasks, or do they tend to change strategies as the learning task changes (Weinstein, Underwood, Wicker, \& Cubberly, 1979)? Finally, we wanted to assess whether learners would be uniformly effective relative to other learners across all of the learning situations or whether a learner's effectiveness relative to that of other learners would vary across the leaming tasks.

A second general issue was embedded in the current research. As noted above, we tested three instructional groups, each of which performed a different semantic/ elaborative encoding activity (category naming, imagery, sentence generation) for each of the three learning situations (paired associate, list learning, vocabulary). The levels-of-processing framework (Craik \& Lockhart, 1972) claims that semantic or elaborative processing
(Craik \& Tulving, 1975) is necessary for good retention; however, within this general theoretical orientation, it is not clear whether or not all processing that is semantic in nature should produce equivalent remembering (Baddeley, 1978). In this paper, we examine the notion that the relative effectiveness of different semantic encoding activities depends in part on the material or learning task. We suggest that, for some learning tasks, all activities leading to semantic processing may be equally effective; for other learning tasks, activity A will be better than activity $B$; and for yet other leaming tasks, activity B will be better than activity A. We label this the "task-appropriate processing hypothesis." According to this hypothesis, the encoding-activity variable will interact with the learning situation in determining memory performance. If this finding were to obtain, it would suggest that less research emphasis be placed on demonstrations showing deeper (or elaborate) processing produces better memory and that researchers focus on an empirical analysis of the relation between different encoding strategies, the to-be-learned materials, and memory.

\section{EXPERIMENT 1}

\section{Method}

Subjects. The subjects were 48 students in an introductor psychology course who participated to receive extra credit toward their course grade. Twelve subjects were assigned randomly to each of four conditions.

Learning materials. Three sets of learning materials were employed. One set was a 33-item structured word list containing 3 words from each of 11 categories. A second set was a 32-item paired-associate list in which the stimulus and response members were highly concrete and imageable nouns [mean concreteness $=6.48$, mean imageability $=6.22$, and mean mean ingfulness $=6.46$; from Paivio, Yuille, \& Madigan (1968) norms] The pairs were haphazardly formed with the constraint that nc pair contain highly associated nouns (e.g., "NURSE-DOCTOR") The third set was a list of 15 unfamiliar words paired with a 3 to 5-word definition. For each set of learning materials, a book let was constructed. The booklet contained one item per page

Procedure. The subjects were assigned randomly to one of four instructional conditions, an "uninstructed" condition, an "imagery" condition, a "sentence" condition, and a "category name" condition. For all conditions, the subjects studied each of the three material sets. After studying each set, the subject: were given a recall test for that material, and, upon having com pleted all three study-test tasks, the subjects were probed as ic the strategies that they had employed for studying each materia set. Following is a detailed description of each of these aspect: of the experiment.

In the "uninstructed" condition, prior to each of the thre learning tasks, the subjects were informed that a list of item: (the particular kind of stimuli that the list comprised was de scribed to the subject) would be presented, after which a mem ory test would be administered. The subjects were urged to per form any mental operations that they thought would be usefu in learning the list. In addition, they were told to "think ou loud" by writing down their thoughts underneath each item or the page. In the other three instructional conditions, the subject: were informed about the memory test and then assigned a par ticular "learning strategy." The instructions described the strategy, provided a concrete example, and stressed that the assigned learning strategy would prove helpful in rememberin! 
the to-be-learned material. In the "imagery" condition, for the word list the subject was instructed to "form an image in your mind that contains the word. As soon as you have thought of an image write it down in the space below the word. For example, if the word 'SNOW' was printed on the page, you would write down a description of an image you have of SNOW." For the paired-associate list, the subject was instructed to "form an image in your mind of the two words interacting with one another...." For the vocabulary list, the subject was instructed to "form an image in your mind that contains the word. For example, if the word was "ENDOMORPHY-a body type characterized as heavy, you would write down a description of an image you have of ENDOMORPHY. Such an image might be a big, fat man named Endo.",

In the "sentence" condition, for all three lists, the subjects were required to write a sentence using the word(s). For the vocabulary list, the subjects were required to write a sentence with the vocabulary word and then to write the sentence again with the word's definition substituted for the word. The example shown the subjects was: "Minnesota Fats is a perfect example of endomorphy. Minnesota Fats is a perfect example of a heavy body type."

In the "category-name" condition, for the word list and vocabulary list, the subjects were instructed to write down two category names for each word: "For example, if the word 'SNOW' was printed on the page you would write down category names for SNOW. One might be 'weather' and the other might be "climate." "For the paired-associate list, the subjects were required to generate one category name for each of the words in the pair.

The order in which each list of materials was administered was counterbalanced within each instructional condition. The subjects were run in groups of one to four. Immediately prior to presentation of the vocabulary list, each subject was given a sheet of 30 words, 15 of which were items in the vocabulary set. The subjects wrote down the definition of any words they knew Each list of materials was presented in a booklet with one item per page. At intervals of $18 \mathrm{sec}$, an electronic tone signaled subjects to turn to the next page in their booklets. Pilot work had indicated that $18 \mathrm{sec}$ was long enough to allow subjects to complete their encoding task, but with little time to spare. For each list, a practice word was included to familiarize the subjects with the task. Upon completing each list of materials, the subjects solved math problems for $2 \mathrm{~min}$, after which $5 \mathrm{~min}$ were given for a recall task. After the word list, a free-recall test was administered; after the paired-associate list, recall was cued with the initial member of each pair; and after the vocabulary list, recall of each word's definition was tested.

After completing the final memory test, the subjects were given three questionnaires, one questionnaire for each of the three learning tasks. The questionnaires were based in part on the Learning Activities Questionnaire developed by Weinstein and her colleagues (Weinstein et al., 1979).' Twenty encoding strategies representing seven categories of strategies were listed on each questionnaire (category headings were not included as part of the questionnaire). The seven categories reflected by the strategies were rote rehearsal (two strategies), relating parts of sounds of items (three strategies), visual imagery (three strategies), verbal elaboration (four strategies), categorization (two strategies), association of emotional reactions or personal experiences (four strategies), and method of loci (two strategies). Across the three questionnaires, care was taken to keep the encoding strategies as similar as possible; minor changes were made as necessary to reflect the change of learning material. The openended question "Did you use a method not listed here? Give example:" was included at the end of each questionnaire.

For each of the three learning tasks, the subjects were required to rate the frequency with which they had used the encoding strategies listed on the questionnaire. The rating scale ranged from 1 to 5 , with 1 indicating no usage and 5 indicating usage on all items in the set. Such a procedure to assess strategy use has been reported elsewhere (Shaughnessy, 1981). For each subject, the order in which the questionnaires were administered paralleled the order in which the subject had encountered the learning tasks.

\section{Results}

Recall. For all analyses, the rejection level was set at .05 . The mean proportions of words recalled as a function of instructional group and learning task are given in Table 1. For the vocabulary set, each subject's proportionrecalled score was based on words that were not correctly defined on the pretest (no subject correctly defined more than one target word on the pretest). To assess the relative effectiveness of the three assigned semantic processing strategies, a two-factor mixed analysis of variance was performed on the recall scores of the three groups that received encoding-strategy instructions. The type of processing strategy significantly affected recall levels $[\mathrm{F}(2,33)=9.47, \mathrm{MSe}=.05]$. In general, imaginal processing produced the highest recall performance, and category processing produced the lowest recall performance. This main effect was qualified by a significant strategy $x$ learning task interaction such that the relative effectiveness of each strategy depended on the particular leaming task $[F(4,66)=13.71, \mathrm{MSe}=.03]$. Simple main-effects tests indicated that recall levels were not affected by type of strategy on the word-list task $(F<1)$, significantly differed on the paired-associate task $[F(2,99)=31.95$,

Table 1

Experiment 1: Mean Proportion of Items Recalled and Standard Deviations as a Function of Learning Strategy and Task

Strategy Instruction

\begin{tabular}{|c|c|c|c|c|c|c|c|c|c|c|c|c|}
\hline \multirow[b]{2}{*}{ Learning Task } & \multicolumn{3}{|c|}{ None } & \multicolumn{3}{|c|}{ Form Image } & \multicolumn{3}{|c|}{ Identify Category } & \multicolumn{3}{|c|}{ Construct Sentence } \\
\hline & $\mathbf{M}$ & SD & $\mathrm{CCS}$ & $\mathbf{M}$ & SD & $\mathrm{CCS}$ & $\mathbf{M}$ & SD & $\mathrm{CCS}$ & $\mathbf{M}$ & SD & $\mathrm{CCS}$ \\
\hline $\begin{array}{l}\text { Vocabulary } \\
\text { Word List } \\
\text { Paired Associate }\end{array}$ & $\begin{array}{l}.80 \\
.67 \\
.56\end{array}$ & $\begin{array}{l}.21 \\
.16 \\
.30\end{array}$ & .60 & $\begin{array}{l}.74 \\
.58 \\
.82\end{array}$ & $\begin{array}{l}.19 \\
.13 \\
.11\end{array}$ & .57 & $\begin{array}{l}.59 \\
.62 \\
.27\end{array}$ & $\begin{array}{l}.17 \\
.15 \\
.25\end{array}$ & .75 & $\begin{array}{l}.58 \\
.57 \\
.75\end{array}$ & $\begin{array}{l}.23 \\
.18 \\
.19\end{array}$ & .46 \\
\hline Mean & .68 & & & .71 & & & .49 & & & .63 & & \\
\hline
\end{tabular}

Note-CCS = category clustering scores. 
MSe $=.03]$, and tended to differ on the vocabulary task $[\mathrm{F}(2,99)=2.88, \mathrm{MSe}=.03, \mathrm{p}<.10]$. Examination of the paired-associate means shows that imagery and sentence instruction were about equally effective (.82 and .75 , respectively) and that both were considerably more effective than category instructions (.27). For the vocabulary task, imagery $(.74)$ was more effective than sentence generation (.58) and category naming (.59).

Inspection of Table 1 reveals that, in general, the "uninstructed" group was able to leam as effectively or better than were the subjects given semantic encoding instructions. Planned comparisons of recall for the "uninstructed" group with recall of the subjects given semantic encoding instructions supported this impression. On the vocabulary task, the "uninstructed" subjects performed significantly better than the semantic orienting subjects (.80 vs. .64 proportion recalled) $[F(1,44)=5.88, \mathrm{MSe}=.04]$. On the word-list task, the mean proportion of words recalled was again higher for the "uninstructed" group (.67 vs. .59), although not reliably so $[F(1,44)=2.41$, MSe $=.02]$. On the pairedassociate task, the comparison was also not significant $(\mathrm{F}<1)$; however, unlike the other learning tasks, the "uninstructed" subjects displayed lower recall than that produced by the subjects in the semantic conditions (.56 vs. .61). Multiple comparisons were used to further analyze these data (experimentwise error rate set at $\alpha=.05$ ). The "imagery" group recalled significantly more items than the "uninstructed" group (.56 for "uninstructed" vs. .82 for "imagery") [t(44) $=2.86$ ], and the "uninstructed" group recalled significantly more than the "category-name" graup (.56 vs. .27) $[\mathrm{t}(44)=3.16$ ].

"Uninstructed" subjects' recall scores for the pairedassociate list were further examined as a function of the encoding strategies each subject reported using. Only those subjects not reporting the use of a strategy determined empirically to be effective (i.e., imagery or sentence generation) performed more poorly than the "imagery" group (and the "sentence" group). Six "uninstructed" subjects reported using neither imagery nor sentence generation frequently (i.e., did not assign a rating of 5 to an imagery or sentence strategy) for the pairedassociate list, and their recall was low (mean $=.36$ ). Six subjects reported using imagery frequently, and their recall was high and comparable to that found for the "imagery" group (mean $=.76)$. Thus, "uninstructed" subjects who were aware of an effective strategy for the pairedassociate list were able to perform well. It is also noteworthy that, of the six subjects who reported having used imagery on the paired-associate task, only one reported using imagery frequently on both of the other learning tasks and two reported that they did not use imagery frequently on either of the other two tasks. Apparently, "uninstructed" subjects varied their encoding strategy as the to-be-learned material varied. More extensive evidence in line with this conclusion is presented in the following section.
To gather more information on strategies used for the word-list task, category-clustering scores were calculated from the recall data (Roenker, Thompson, \& Brown's, 1971, adjusted-ratio-of-clustering method was used). These scores can range from 1.0 to -1.0 , where a score of 1.0 indicates perfect clustering, 0 indicates no clustering, and a negative score indicates that a number of items were recalled from each category but that they were not recalled in units (see Table 1 for mean clustering scores). Neither an analysis of variance $[F(3,44)=$ 1.86] nor Dunn's multiple comparison procedure (with experimentwise error rate at $\alpha=.05$ ) revealed significant differences between the groups.

Finally, correlations of recall between learning situations were computed for each group, and these are displayed in Table 2 . The only reliable correlation found was between the vocabulary task and the paired-associate task for the "sentence" group $[\mathrm{r}(10)=.70]$.

Questionnaire responses of instructed subjects. For each strategy item on the questionnaire, the mean rated frequency of usage was calculated. ${ }^{2}$ Table 3 lists the three strategy items rated as having been most frequently used (along with each average rating) as a function of instructional group and learning task. Inspection of this table indicates that group instructed to use a particular processing strategy complied, in general, with the instructions. There were two apparent exceptions to this pattern. First, the group instructed to write sentences reported that they most frequently tried to think of category names for the word-list task. However, this group's second most frequently rated strategy was the

Table 2

Correlations of Recall Across the Learning Tasks

\begin{tabular}{|c|c|c|c|}
\hline \multirow[b]{2}{*}{ Strategy Assignment } & \multirow[b]{2}{*}{ Learning Task } & \multicolumn{2}{|c|}{ Learning Task } \\
\hline & & $\begin{array}{c}\text { Vocab- } \\
\text { ulary }\end{array}$ & $\begin{array}{l}\text { Word } \\
\text { List }\end{array}$ \\
\hline & Experiment 1 & & \\
\hline None & $\begin{array}{l}\text { Word List } \\
\text { Paired Associate }\end{array}$ & $\begin{array}{l}.29 \\
.26\end{array}$ & .26 \\
\hline Form Image & $\begin{array}{l}\text { Word List } \\
\text { Paired Associate }\end{array}$ & $\begin{array}{r}.09 \\
-.18\end{array}$ & -.51 \\
\hline Identify Category & $\begin{array}{l}\text { Word List } \\
\text { Paired Associate }\end{array}$ & $\begin{array}{l}.45 \\
.43\end{array}$ & .16 \\
\hline Construct Sentence & $\begin{array}{l}\text { Word List } \\
\text { Paired Associate }\end{array}$ & $\begin{array}{l}.03 \\
.70^{*}\end{array}$ & .11 \\
\hline & Experiment 2 & & \\
\hline None & $\begin{array}{l}\text { Word List } \\
\text { Paired Associate }\end{array}$ & $\begin{array}{l}.35 \\
.41\end{array}$ & .14 \\
\hline Self Chosen & $\begin{array}{l}\text { Word List } \\
\text { Paired Associate }\end{array}$ & $\begin{array}{l}.54 \\
.79 *\end{array}$ & $.58^{*}$ \\
\hline Appropriate & $\begin{array}{l}\text { Word List } \\
\text { Paired Associate }\end{array}$ & $\begin{array}{l}.51 \\
.26\end{array}$ & .37 \\
\hline Haphazard & $\begin{array}{l}\text { Word List } \\
\text { Paired Associate }\end{array}$ & $\begin{array}{l}-.08 \\
-.69^{*}\end{array}$ & .17 \\
\hline
\end{tabular}

*Significantly different from $o, p<.05$. 
Table 3

Experiment 1: The Three Most Frequently Used Strategies as a Function of Instruction and Learning Task

\begin{tabular}{|c|c|c|}
\hline Strategy Instruction & Learning Task & Strategy Reported (Mean Frequency of Use) ${ }^{\mathbf{a}}$ \\
\hline \multirow[t]{3}{*}{$\begin{array}{l}\text { Form } \\
\text { Image }\end{array}$} & Vocabulary & $\begin{array}{l}\text { "Iormed a picture or image of each word and its meaning" ( } 3.75) \text {; "Thought about the } \\
\text { definition in your own words" }(3.25) \text {; "Related the word to a personal experience" }(3.08) \text {. }\end{array}$ \\
\hline & Word List & $\begin{array}{l}\text { "Formcd a picture or image of each word in your mind" }(4.25) \text {; "Related each word with a } \\
\text { personal experience" }(3.58) \text {; "Related each word to a descriptive adjective" }(3.50) \text {. }\end{array}$ \\
\hline & Paired Associate & $\begin{array}{l}\text { "Iormed a picture or image of both items doing something together" }(3.92) \text {; "Pictured an } \\
\text { image of both items in your mind side by side" ( } 3.08) \text {; "Made up a story or sentence using } \\
2 \text { or more word pairs" ( } 3.08) \text {; "Related the word-pair to a personal experience" }(3.08) \text {. }\end{array}$ \\
\hline \multirow[t]{3}{*}{$\begin{array}{l}\text { Identify } \\
\text { Category }\end{array}$} & Vocabulary & $\begin{array}{l}\text { "Thought about the definition in your own words" }(3.67) \text {; "Repeated the meaning of each } \\
\text { word to yourself" }(3.33) \text {; "Formed a picture or image of each word and its meaning" }(3.25) \text {. }\end{array}$ \\
\hline & Word List & $\begin{array}{l}\text { "Grouped words together according to category or class, such as animal, vegetable, mineral, } \\
\text { and so on" }(4.17) \text {; "Tried to think of category names for each word" (4.08); "Formed a } \\
\text { picture or image of each word in your mind" (3.58). }\end{array}$ \\
\hline & Paired Associate & $\begin{array}{l}\text { "Thought of a category name for each word in the pair" (3.25); "Pictured an image of both } \\
\text { items in your mind side by side" (3.08); "Formed a picture or image of both items doing } \\
\text { something together" (3.08). }\end{array}$ \\
\hline \multirow[t]{3}{*}{$\begin{array}{r}\text { Construct } \\
\text { Sentence }\end{array}$} & Vocabulary & $\begin{array}{l}\text { "Made up a sentence with the word" (4.21); "Thought about the definition in your own } \\
\text { words" (3.92); "Repeated the meaning of each word to yourself" }(3.0) \text {. }\end{array}$ \\
\hline & Word List & $\begin{array}{l}\text { "Grouped words together according to category or class, such as animal, vegetable, mineral } \\
\text { and so on" ( } 3.33) \text {; "Made up a sentence containing one of the words" }(3.25) \text {;"Formed a } \\
\text { picture or image of each word in your mind" }(3.25) \text {. }\end{array}$ \\
\hline & Paired Associate & $\begin{array}{l}\text { "Made up a phrase or sentence using both members of a pair" }(4.17) \text {; "Thought about the } \\
\text { similarity and differences between the meanings of the } 2 \text { words" ( } 3.42) \text {; "Pictured an image } \\
\text { of both items in your mind side by side" }(2.83) \text {. }\end{array}$ \\
\hline \multirow[t]{3}{*}{ None } & Vocabulary & $\begin{array}{l}\text { "Repeated the meaning of each word to yourself" }(3.83) \text {; "Thought about the definition in } \\
\text { your own words" }(3.75) \text {; "Formed a picture or image of each word and its meaning" }(3.58) \text {. }\end{array}$ \\
\hline & Word List & $\begin{array}{l}\text { "Formed a picture or image of each word in your mind" (3.92); "Grouped words } \\
\text { together according to category or class ..." (3.67); "Tried to think of category names } \\
\text { for each word" (3.42); "Related each word to another word with similar meaning" (3.42). }\end{array}$ \\
\hline & Paired Associate & $\begin{array}{l}\text { "Thought about the similarity and differences between the meanings of the } 2 \text { words" } \\
\text { (3.25); "Formed a picture or image of both items doing something together" (3.17); "Pic- } \\
\text { tured an image of both items in your mind side by side" (3.08). }\end{array}$ \\
\hline
\end{tabular}

${ }^{a}$ Ratings ranged between 1 ("Never") and 5 ("Always").

sentence strategy, and the mean frequency rating for this sentence strategy was just below that reported for the category-name strategy $(3.25$ and 3.33 , respectively). Informal perusal of the booklets that the subjects used to perform the encoding task verified that the subjects in the "sentence" group did write sentences. Moreover, the content of the sentences frequently expressed subordinate-superordinate relationships. Thus, the content of the generated sentences seems to underlie the relatively high rating given the category-naming strategy. Based on these additional observations, it is reasonable to conclude that the subjects instructed to write sentences did comply with the instructions for the word-list task. Furthermore, it is important to note that the rated frequency of use of strategies did accurately represent the kinds of processing the subjects apparently performed.

The condition in which the subjects were instructed to generate category names for the vocabulary words was the other instance in which the subjects' frequencyof-use ratings were seemingly not consistent with the encoding instructions. The instructed strategy (in this case, category naming) was rated fourth highest; how- ever, the average frequency rating for the instructed strategy was not far different from that for the highest rated strategy ( 3.16 vs. 3.67 , respectively). Also, informal analysis of the orienting responses indicated that most subjects tried to comply with the instructions. For words easily categorized (e.g., "PONGID"), the subjects wrote down category names. Some words, however, were relatively difficult to categorize; for these words, the subjects tended to write down semantic associates rather than, or in addition to, category names. For example, typical responses to "VELODROME" included "dirt bike," "jump," "bicycle," and "races."

Questionnaire responses of "uninstructed" subjects. Examination of Table 3 reveals that for "uninstructed" subjects the most frequently used strategy varied as a function of the learning task, although some commonality in strategy use was maintained (e.g., the use of imagery). Even though these data suggest that "uninstructed" subjects employed different learning strategies across the three learning situations, the group means could mask patterns for individuals. Therefore, an analysis based on each individual's responses was performed. For each learning task. all strategies that a subject used frequently 
(rated a "5") were recorded. ${ }^{3}$ For each subject, a repetition count was obtained by noting the strategies that occurred for more than one task and summing the number of times the "repeated" strategies occurred. Then a repetition ratio was calculated by dividing the repetition count by the total number of strategies that the subject had used across all three tasks. The ratio is an index of the degree to which each individual relied on one strategy or cluster of strategies for all three learning tasks. The index asymptotes at 0 and 1;0 indicates utilization of completely different strategies across tasks, and 1 indicates use of the same strategy(ies) across tasks.

The observed ratio scores ranged from 0 to .67 , with a mean of .43. Thus, no "uninstructed" subject used the same set of strategies for all learning tasks, and only two used completely different strategies across the learning tasks. This pattern is consistent with the pattern found for the frequency-of-use means reported above. Both sets of results converge to suggest that learners have a general strategy cluster that they augment with different specific strategies, depending on the learning task.

\section{Discussion}

Several important trends were found in the performance of subjects not instructed to perform any particular encoding activity. These will be stated briefly; more complete discussion will follow the description of a second experiment in which these findings are replicated. (1) Learners were not relying exclusively, or even moderately, on maintenance rehearsal to leam. (2) Learners were not depending on one particular encoding strategythey used different clusters of strategies as the learning materials changed. Furthermore, learners were employing their available array of strategies in a task-appropriate fashion. This is evidenced by the generally comparable recall scores for "uninstructed" subjects and subjects assigned the encoding strategy most appropriate for the material to be learned. (3) The nonsignificant correlations for recall across the three learning situations suggests that the subjects' skills were not uniform across the learning situations. That is, the relative skill displayed by leamers changed as a function of the learn. ing task.

A second noteworthy aspect of the results is the pattem of recall for the groups assigned semantic encoding activities. These data demonstrate that the relative effectiveness of encoding activities varies depending on the learning situation. For the word-list task, all encoding activities were equally effective. McDaniel and Masson (1977) reported that, for a similar list of words, generating category names and generating adjectives also produces equivalent recall. Assuming that category naming is more of an organizational type of semantic processing than are the other assigned strategies, it may at first blush seem surprising that category naming would not produce reliably higher recall and clustering scores (Battig \& Bellezza, 1979). Kail and Siegel (1977), however, showed that encoding of taxonomic features is performed "routinely and automatically" (p. 80); also, it appears that organizational processing, although necessary for good delayed recall $(24 \mathrm{~h})$, is useful but not necessary for immediate recall (McDaniel \& Masson, 1977). For some learning situations, then, the particular semantic strategies that are employed are not critically important for memory, perhaps in part because the description of the event that occurs automatically (Kail \& Siegel, 1977) is mnemonically effective.

The semantic strategies were not equivalent in the paired-associate task, a task for which successful performance depends on establishing linkages between the items in each pair (Baddeley, 1976; Pressley, Levin, Kuiper, Bryant. \& Michener, 1982). In this task, the semantic strategies that encouraged the formation of such linkages (imagery and sentence generation) were more effective than the strategy that did not encourage linkages (category naming). For the vocabulary-learning task, the relative effectiveness of the strategies changed once again. Sentence generation and category naming produced equivalent recall, and this level of recall tended to be worse than that produced by the imagery strategy. This pattern is consistent with results in the vocabularylearning literature (Gipe, 1981; Pressley, Levin, \& Miller, 1982). As Pressley et al. (1982) noted, mnemonically effective vocabulary-learning strategies have very specific characteristics: The stimuli must be recoded such that the associative link between the vocabulary word and its definition is strengthened. Apparently, neither the sentence-generation strategy nor the category-naming strategy is as effective as the imagery strategy (as implemented here) in producing the necessary mediating link between an unfamiliar vocabulary item and its definition. This was true despite the fact that the sentence-generation strategy included an additional component to the usual instructions to generate a meaningful sentence containing the vocabulary item (Gipe, 1981; Pressley, Levin, \& Miller, 1982). The sentence strategy instructions additionally directed subjects to rewrite each sentence by substituting the definition for the vocabulary item. It seems that creating a sentence frame common to both the vocabulary word and the definition is not sufficient to strengthen the link between a vocabulary item and its definition.

Of further interest are the correlations of recall between tasks. The lack of significant correlations for all strategy groups except the "sentence" group suggests that the effectiveness of an imagery or category strategy for one individual relative to another is not necessarily invariant across tasks. For the "sentence" strategy, on the other hand, individual differences in generating mnemonically effective sentences appears to be consistent across associative learning tasks (paired associate and vocabulary). The sentence strategy seems to be less 
precise than the other strategies in specifying the informational content to be included (this surfaced in the strategy-assessment data). Perhaps such flexibility allows differences in subjects' metamemorial abilities to be manifested. For instance, it may be that some subjects try to generate a sentence specifying an elaborate or precise interaction between the to-be-associated items, whereas other subjects simply try to generate any sentence. Although speculative, these notions suggest interesting directions for further work.

The strategy-assessment data for the groups assigned an encoding activity are also illuminating. The frequencyof-use ratings suggest that the subjects did employ the assigned strategy, but the subjects also reported using strategies aside from the one instructed. It seems, then, from this experiment, as well as others (see Montague, 1972), that instructions to use one particular strategy do not preclude subjects from employing other strategies (especially in an intentional learning situation). Nevertheless, in the present study, the instructed strategy seemed to be of primary importance in determining memory performance. For instance, the "categoryname" group reported that they used an interactiveimagery strategy almost as frequently as they used the category-name strategy for the paired-associate task, yet recall for this group was low and significantly different from that of the "imagery" group. It may be that, despite trying to employ additional encoding activities, the subjects had only enough time to complete satisfactorily the assigned strategy. Time constraints have been shown to limit memory effects due to idiosyncratic encoding efforts (McDaniel \& Masson, 1977).

In sum, the results suggest that the task appropriateness of an encoding activity influences the extent to which the encoding activity produces good retention. The General Discussion addresses how this framework relates to the similar, but less general, notion of "transfer appropriate processing" (Morris, Bransford, \& Franks, 1977; see also McDaniel, Friedman, \& Bourne, 1978). The task-appropriate processing notion has implications for learning-strategy instruction. Consider the situation in which one is attempting to derive an effective encoding strategy for each of several different learning tasks confronted by a student. One approach to this situation has been to generate encoding or learning strategies based on levels-of-processing notions (Schmeck, 1983; Weinstein et al., 1979). That is, students are instructed to use a learning strategy that involves deep or elaborate processing of the material. The task-appropriate processing principle suggests that memory performance is improved by employing a particular semantic or elaborative processing strategy for certain learning situations but not for others. The implication of this principle is that, as the learning task changes, the assignment of a different encoding strategy should be considered. In situations in which the learner encounters different tobe-learned materials, assignment of encoding strategies that are appropriate for the materials to be learned should produce higher levels of learning than haphazard selection of semantic encoding strategies. Experiment 2 was designed to test this prediction and to gather additional data on the spontaneous strategy use of mature learners.

\section{EXPERIMENT 2}

In this experiment, a different semantic processing strategy was paired with each set of learning materials. For one group of subjects (labeled "appropriate"), this pairing was consistent with the empirically determined task appropriateness of each semantic strategy investigated in Experiment 1. For another group of subjects (labeled "haphazard"), assignment of strategies to each learning situation was chosen such that it was not consistent with the task appropriateness of the strategies. It was expected that the assignment of semantic strategies based on the task-appropriateness principle would result in better memory performance than the assignment of semantic strategies that was not necessarily task appropriate.

Two additional conditions were incorporated into this experiment. In light of other evidence that subjects seemingly are not aware of effective learning strategies or are not aware of the conditions under which different encoding strategies are most effective (e.g., Mazuryk \& Lockhart, 1974; Shaughnessy, 1981), it was important to replicate the relatively sophisticated use of encoding strategies for the subjects not instructed to use any particular encoding strategy. Accordingly, a third group of subjects ("uninstructed") was not informed of any particular encoding strategies for remembering the stimuli.

A fourth condition was included to shed light on the following issue. The results from Experiment 1 had indicated that subjects can effectively match encoding strategies with learning tasks. Perhaps, though, this kind of metamemorial knowledge (Pressley, Borkowski, \& O'Sullivan, in press) is limited to only those strategies that the learner spontaneously employs. Can learners effectively match experimenter-provided strategies to different learning tasks? The fourth group of subjects was included to gather information on this question. This group (labeled "self-chosen") was given the choice of which of three strategies (category naming, imagery, and sentence generation) to use on each of the leaming tasks. If learners are sensitive to the task appropriateness of experimenter-provided strategies, they should select the appropriate study strategies and demonstrate recall superior to "haphazard" subjects; if not, they should perform no better than "haphazard" subjects.

\section{Method}

Subjects. The subjects were 48 students in an introductory psychology course participating to receive extra credit points 
toward their course grade. Twelve subjects were assigned randomly to each of four conditions.

Procedure and Materials. The to-be-learned materials were identical to those used in Experiment 1. The encoding strategies were also the same, with the exception that the imagery-encoding instructions had subjects sketch, rather than describe, their images. The subjects in the "appropriate" group were instructed to perform imagery encoding on the vocabulary list, category naming on the word list, and sentence generation on the pairedassociate list. The subjects in the "haphazard" group were instructed to use sentence generation for the vocabulary list, imagery for the word list, and category naming on the pairedassociate list. The "self-chosen" subjects were given instructions on all three encoding strategies prior to each list of materials. The instructions stressed that, for a particular list, the subjects should use one, and only one, strategy. In all other respects, the acquisition procedure was the same as that used in Experiment 1 .

The questionnaire instructions differed from those used in Experiment 1 . The subjects were instructed to indicate which of the 20 listed strategies they had employed and then to rankorder those strategies in terms of frequency of use. Rankings were used instead of ratings in order to determine the primary strategy employed by each individual for each task.

\section{Results and Discussion}

Recall. As in Experiment 1, the rejection level for statistical tests was set at .05 . Table 4 displays the mean proportions recalled as a function of strategy assignment and learning task. Planned comparisons of the average recall for the "haphazard" group with the average recall for each of the other groups revealed that, as expected, haphazard assignment led to significantly worse overall performance than did appropriate assignment (.56 and .70 , respectively) $[\mathrm{F}(1,44)=4.33, \mathrm{MSe}=.03]$. The "haphazard" group also recalled significantly less than the "self-chosen" group $(.73)[\mathrm{F}(1,44)=6.60, \mathrm{MSe}=$ .03 and tended to recall less than the "uninstructed" group $(.67)[\mathrm{F}(1,44)=3.10, \mathrm{MSe}=.03, \mathrm{p}<.10]$. Inspection of the means representing performance for each learning task shows that the general pattern just described was most prominent for the vocabulary and paired-associate lists; on the word list, the "haphazard" group showed little, if any, decrement relative to the other groups. Statistical comparisons between the "haphazard" condition and the other conditions for each individual learning task supported these impressions. None of the comparisons of recall for the wordlist task approached significance, including comparisons for category-clustering scores (see Table 4 for clustering means). On the paired-associate task, appropriate strategy assignment led to significantly higher recall than haphazard assignment (.66 and .41 , respectively) $[\mathrm{F}(1,44)=6.05$, MSe $=.06]$, and no strategy instruction (.60) tended to produce higher recall than haphazard assignment $[\mathrm{F}(1,44)=3.61$, MSe $=.06, \mathrm{p}<.10 \mathrm{]}$. Self-chosen assignment (.60) also produced a marginally significant increase in recall on the paired-associate task $[\mathrm{F}(1,44)=3.72$, MSe $=.06$, $p<.10$ ] and a significant increase on the vocabulary task $(.82$ and .55 , respectively) $[\mathrm{F}(1,44)=5.15$, MSe $=.08]$. Furthermore, average recall for the "selfchosen" group was comparable to that for the "appropriate" group $(F<)$. This result implies that learners who are provided with a set of strategies can appropriately match a particular strategy with a learning task.

Correlations of the subjects' recall across learning tasks were again computed (see Table 2). Except for the "self-chosen" group, an individual's effectiveness relative to that of other subjects was not invariant across tasks (as in Experiment 1). In the "haphazard" group, there was a significant negative association between paired-associate learning and vocabulary learning. Interestingly, in the "self-chosen" group, the correlations were positive and consistently high, with two of three being significant. This result could imply either that individuals were somewhat consistent in terms of how appropriately they selected strategies or that individuals were consistent in terms of how effectively they performed an appropriate set of strategies (as in the "sentence" group from Experiment 1). To explore these possibilities, the strategy most frequently used by the "self-chosen" subjects on each task (reported in the questionnaire) was examined. Of the six subjects who averaged the highest recall ( $89 \%$ recall as a group), five selected one of the instructed strategies that was appropriate on at least two of the three tasks. In contrast, of the remaining six subjects (57\% recall as a group), only one subject did so, and even this subject reported that, for the paired-associate task, he or she "imaged the items side by side" (rather than forming an interactive image). This modification to the instructed strategy would be expected to reduce the effectiveness of the imagery strategy (Wollen, Weber, \& Lowry, 1972). Two subjects displaying low recall selected instructed strategies that were

Table 4

Experiment 2: Mean Proportion of Items Recalled and Standard Deviations as a Function of Strategy Assignment and Leaming Task

\begin{tabular}{|c|c|c|c|c|c|c|c|c|c|c|c|c|}
\hline \multirow[b]{2}{*}{ Learning Task } & \multicolumn{3}{|c|}{ None } & \multicolumn{3}{|c|}{ Self-Chosen } & \multicolumn{3}{|c|}{ Appropriate } & \multicolumn{3}{|c|}{ Haphazard } \\
\hline & $\mathbf{M}$ & SD & $\mathrm{CCS}$ & $\mathbf{M}$ & SD & $\operatorname{ccs}$ & $\mathbf{M}$ & $\mathrm{SD}$ & $\mathrm{CCS}$ & $\mathbf{M}$ & $\mathrm{SD}$ & CCS \\
\hline $\begin{array}{l}\text { Vocabulary } \\
\text { Word List } \\
\text { Paired Associate }\end{array}$ & $\begin{array}{l}.77 \\
.65 \\
.60\end{array}$ & $\begin{array}{l}.25 \\
.13 \\
.20\end{array}$ & .59 & $\begin{array}{l}.82 \\
.76 \\
.60\end{array}$ & $\begin{array}{l}.20 \\
.20 \\
.32\end{array}$ & .55 & $\begin{array}{l}.69 \\
.74 \\
.66\end{array}$ & $\begin{array}{l}.31 \\
.18 \\
.17\end{array}$ & .69 & $\begin{array}{l}.55 \\
.70 \\
.41\end{array}$ & $\begin{array}{l}.37 \\
.21 \\
.27\end{array}$ & .67 \\
\hline Mean & .67 & & & .73 & & & .70 & & & .56 & & \\
\hline
\end{tabular}

Note-CCS = category clustering scores. 
inappropriate for two of the three tasks, and two other subjects reported eschewing the instructed strategies for rote rehearsal. Together, these data suggest that, despite the trend for "self-chosen" subjects to perform relatively well as a group, there are individual differences in terms of how appropriately learners can select explicitly provided strategies to accomplish a set of learning tasks. The present results fit in nicely with current theoretical positions holding that important components underlying individual differences in memory performance (in addition to knowledge about how to perform specific learning routines) are metamemorial knowledge about why various encoding strategies are necessary and effective and knowledge about their range of utility (Kendall, Borkowski, \& Cavanaugh, 1980; Palincsar \& Brown, in press).

As a whole, the results indicate that simply utilizing semantic encoding strategies for learning a variety of stimulus materials is not sufficient to ensure optimal retention. A particular semantic encoding strategy can be less appropriate for the learning task than another semantic strategy. Thus, a learner who applies semantic strategies that are not appropriate for the learning task will be less effective, in general, than a learner who applies available strategies in a taskappropriate fashion. With regard to implications for learning in educational settings, given that the learning materials used for this experiment represent a restricted range of the kind of material typically encountered by a student, it seems possible that this experiment understates the potential decrement that could accrue from insensitivity to the task appropriateness of learning strategies.

Questionnaire responses. For each strategy item on the questionnaire used by at least 5 of 12 subjects, the mean rank was calculated. ${ }^{4}$ Table 5 lists the top two ranked strategies, along with the percentage of subjects who indicated that they had used these strategies. For the groups that received strategy instructions, on all tasks the instructed strategies were used by a higher percentage of subjects than were any other strategies, except by the "self-chosen" group on the vocabulary task. Moreover, the percentages of subjects who reported using the instructed strategies indicated that, for the most part, all or nearly all of the subjects who received strategy instructions performed the instructed strategy,

Table 5

Experiment 2: Most Frequently Used Strategies

\begin{tabular}{|c|c|c|}
\hline Strategy Instructions & Learning Task & Strategy Reported ${ }^{a}$ \\
\hline \multirow[t]{3}{*}{ Appropriate Assignment ${ }^{b}$} & Vocabulary & $\begin{array}{l}\text { "Formed a picture or image of each word and its meaning" }(92 \%, 1.4) \text {; "Repeated } \\
\text { the meaning of each word to yourself" }(58 \%, 2.4) \text {. }\end{array}$ \\
\hline & Word List & $\begin{array}{l}\text { "Grouped words according to category..." }(100 \%, 1.4) \text {; "Tried to think of } \\
\text { category names..." }(73 \%, 1.9) .\end{array}$ \\
\hline & Paired Associate & $\begin{array}{l}\text { "Made up a } \ldots \text { sentence using both members of a pair" }(91 \%, 1.3) \text {; "Formed a } \\
\text { picture or image of both items doing something together" }(64 \%, 1.7) \text {. }\end{array}$ \\
\hline \multirow[t]{3}{*}{ Haphazard Assignment ${ }^{c}$} & Vocabulary & $\begin{array}{l}\text { "Made up a sentence with the word" }(83 \%, 2.0) \text {; "Related each word with a person } \\
\text { you know" }(58 \%, 1.9) \text {. }\end{array}$ \\
\hline & Word List & $\begin{array}{l}\text { "Formed a picture or image of each word..." }(100 \%, 1.9) ; \text { "Grouped words together } \\
\text { according to category..." }(42 \%, 1.4) \text {. }\end{array}$ \\
\hline & Paired Associate & $\begin{array}{l}\text { "Thought of a category name for each word in the pair" }(64 \%, 1.3) \text {; "Formed a } \\
\text { picture or image of both items doing something together" }(45 \%, 2.8) \text {. }\end{array}$ \\
\hline \multirow[t]{3}{*}{ Self-Chosen ${ }^{d}$} & Vocabulary & $\begin{array}{l}\text { "Thought about definition in own words" }(58 \%, 2.3) \text {; "Made up a sentence with } \\
\text { the word" }(50 \%, 2.0) \text {. }\end{array}$ \\
\hline & Word List & $\begin{array}{l}\text { "Grouped words together by category..." }(64 \%, 3.9) \text {;"Made up a sentence con" } \\
\text { taining } 1 \text { of the words" }(45 \%, 3.2) \text {. }\end{array}$ \\
\hline & Paired Associate & $\begin{array}{l}\text { "Made up a ... sentence using both members of the pair" }(55 \%, 1.5) \text {; "Pictured } \\
\text { an image of both items in your mind side by side" }(55 \%, 2.5) .\end{array}$ \\
\hline \multirow[t]{3}{*}{ None } & Vocabulary & $\begin{array}{l}\text { "Formed a picture or image of each word and its meaning" }(50 \%, 3.0) \text {; "Repeated } \\
\text { the meaning of each word to yourself" }(42 \%, 2.4) \text {; "Tried to find a similar sound } \\
\text { pattern between each word and its meaning" }(42 \%, 2.4) \text {. }\end{array}$ \\
\hline & Word List & $\begin{array}{l}\text { "Formed a picture or image of each word in your mind" }(50 \%, 2.5) \text {; "Grouped words } \\
\text { together according to category ..." }(42 \%, 1.8) .\end{array}$ \\
\hline & Paired Associate & $\begin{array}{l}\text { "Formed a picture or image of both items doing something together (i.e., inter- } \\
\text { acting in some way)" }(42 \%, 1.6) \text {; "Pictured an image of both items in your mind } \\
\text { side by side" }(42 \%, 2.2) \text {. }\end{array}$ \\
\hline
\end{tabular}

"For this questionnaire, the subjects were instructed to rank-order the strategies they used. The numbers in parentheses are the percentages of subjects who indicated they used the listed strategy and the mean ranking these subjects assigned that strategy. bimagery assigned to vocabulary, category naming to word list, and sentence generation to paired-associate list. 'Sentence generation assigned to vocabulary, imagery to word list, and category naming to paired-associate list. 'The subjects were instructed to choose one of the three strategies for each task. 
and generally the instructed strategy was ranked as being the most frequently employed strategy. Thus, it appears that the subjects were able to comply with the strategy instructions. The remainder of this section presents analyses describing the pattern of strategy for the "uninstructed" subjects.

As in Experiment 1, the "uninstructed" group displayed variation in the particular strategies employed across learning tasks, as well as some commonality. Imagery was highly ranked for all three tasks, but the other highly ranked strategies were used extensively for only one of the tasks. Within this general pattern, large individual differences were evident. For each task, at least 7 different strategies were ranked as being the most frequently used ( 7 for paired associate, 9 for vocabulary, and 10 for word list). Analysis of each subject's strategyuse pattern reinforced the impressions from the above analyses. For each learning task, at least $83 \%$ of the subjects reported using more than one processing strategy to learn the material; on average, the subjects reported using just over 3 different processing strategies per learning task ( 3.25 for word list, 3.42 for paired associate, and 3.08 for vocabulary). Moreover, a subject's primary strategy varied with the learning task: $58 \%$ of the subjects used a different primary strategy on each task, whereas the remaining $42 \%$ used a different strategy on two of the three tasks. (The average number of different primary strategies used across tasks was 2.6 of a possible 3.0.) A strategy-repetition ratio like that computed in Experiment 1 was also calculated for each subject. The strategy cluster on which the repetition ratio was based included each subject's reported primary strategy and, if reported, secondary and tertiary strategies. The observed scores ranged from 0 to .90 , with a mean of .41. This result parallels that obtained in Experiment 1 with absolute-frequency ratings. The questionnaire results from both experiments, then, converge to support the assertion that, in general, subjects who do not receive strategy instructions will attempt to learn a set of items with a strategy that combines encoding processes that are unique to the material with encoding processes that tend to be utilized over a variety of materials.

\section{GENERAL DISCUSSION}

Two important findings emerged from this research. First, the subjects who were not instructed to perform an experimenter-provided encoding strategy spontaneously employed a variety of learning strategies across several learning tasks, and these strategies were for the most part effective. Second, the relative effectiveness of the experimenter-provided semantic encoding strategies was found to vary as a function of the learning task. Each of these findings will be discussed in turn.

In two experiments, the subjects not instructed on an encoding strategy utilized processing strategies that were more sophisticated than those that sometimes have been attributed to mature learners. Some researchers have hypothesized that college students believe that rote rehearsal is an effective learning strategy (Norman, 1978) and that students will use this strategy unless otherwise instructed (Mazuryk \& Lockhart, 1974). For the present learning tasks, rote rehearsal was generally not relied upon extensively or predominately; even when subjects reported relying on rote rehearsal (e.g., vocabulary learning), they supplemented it with imaginal and elaborative processing. This finding is in line with other studies that have reported that most mature learners spontaneously utilize leaming strategies that are more sophisticated than rote rehearsal (learning a series of pictures-Barclay, 1979; prose learning-Brown \& Smiley, 1978; learning concrete noun pairs-Pressley \& Levin, 1977). Apparently, extensive reliance on rote rehearsal is more of an exception than a rule for adult learners.

Are the strategies, then, that adult learners rely on effective? The subjects in this study were spontaneously performing effective encoding/recoding activities, as evidenced by the generally equivalent (or, in some cases, superior) recall of the "uninstructed" group and the groups assigned semantic/elaborative encoding strategies. One might wonder whether such mnemonically effective strategy use might be limited to adults with relatively high academic ability (a characteristic of the population from which the present subjects were selected; see McDaniel \& Pressley, in press). Some support for this idea can be found in results from the vocabulary-learning literature. Using subjects from the same university sampled in the current study, McDaniel and Pressley (in press, Experiment 1) found no significant differences in vocabulary learning between uninstructed control subjects and subjects instructed to use the keyword method, implying that control subjects were employing strategies as effective as the highly effective keyword method. On the other hand, studies using subjects from less academically selective universities have found large and significant differences between uninstructed control subjects and keyword subjects (cf. McDaniel \& Pressley, in press).

Counter to the idea that only high-ability college students spontaneously display effective strategies are the results of work in the paired-associate domain. Rohwer and Bean (1973, Experiment 2) reported that uninstructed high school students performed comparably to a sentence-construction instructional group, and Pressley and Levin (1977) found that $94 \%$ of a group of 15-year-old subjects spontaneously used elaboration at least some of the time to learn a list of paired concrete nouns. In that vocabulary learning is a more complex associative task (Pressley, Levin, \& Bryant, 1982), it is possible that task complexity interacts with academic ability in determining the effectiveness of the strategies employed by mature learners. Clearly, more work 
specifically designed to explore the relationship between academic ability and the effectiveness of learning strategies as a function of task complexity is merited.

The present results are consistent with those of other studies (see Pressley \& Levin, 1977) in demonstrating that, across a group of learners, there are large individual differences in the kinds of strategies that are spontaneously employed (e.g., in Experiment 2, for every task at least seven different strategies were ranked as most frequently used). This study further indicates that individual learners will rely on a variety of encoding strategies in attempting to learn verbal material. Battig and his colleagues (see Battig, 1975), using numerous strategy-assessment procedures, also reported that, for paired-associate and word-list learning tasks, individuals varied the type of processing used on particular items in a list. Battig did not, however, examine individual strategy variation across tasks. The present strategy-assessment data imply that learners utilize a variety of strategies across learning tasks as well as within a verbal learning task. Moreover, it appears that learners utilize some processes uniquely for a particular leaming task and utilize other processes somewhat consistently over a variety of materials. Given the interaction obtained between processing strategies and learning task for instructed subjects, the variation in strategy use appears to be quite functional. Varying encoding strategies for items within a list has also been found to enhance retention (Einstein, McDaniel, \& Battig, 1978).

The interaction noted above implies that the effectiveness of an encoding activity is not simply a function of the depth (Craik \& Lockhart, 1972) or elaborateness (Craik \& Tulving, 1975) to which an item is encoded. Researchers have proposed the notion of transferappropriate processing (Morris et al., 1977; see also McDaniel et al., 1978) to indicate that the effectiveness of an encoding activity depends not only on the type of processing induced, but also on the criterial task. The present findings suggest that a broader construct, task-appropriate processing, is needed to capture the variability in the effectiveness of different types of processing. The idea here is that any of several aspects of the learning task influence which encoding process will most enhance retention. These aspects include not only the criterial task, but also the materials to be learned. This formulation is compatible with recent memory models wherein factors such as materials, encoding tasks, and criterial tasks are important determinants of memory (e.g., Jenkins, 1979).

How could the type of material influence the effectiveness of the encoding strategy? One idea is that the effectiveness of the encoding strategy depends on whether or not the encoding strategy promotes the encoding of requisite information not activated by the material itself (Hunt \& Einstein, 1981). This notion appears useful in explaining the differences in the effectiveness of the strategies on the paired-associate list as well as the similarities of the strategies on the word list. Since the paired-associate list was composed of randomly paired nouns, any relational information shared by the words in most pairs was not especially salient. Thus, the encoding strategies leading to encoding of information relating the items of the pair (i.e., interactive images, sentences) would be more beneficial than the strategy (category naming) leading to encoding of easily or automatically activated taxonomic information (Kail \& Siegel, 1977) not useful in forming the needed linkages. For materials in which such easily activated taxonomic information is useful (e.g., the structured word list), however, many semantic strategies are effective. By this analysis, depending on the materials, paired-associate and word-list tasks could also yield an opposite pattern of results. For example, it if were the case that the items in each pair were strongly associated (for instance, were from the same taxonomic category), then most any semantic strategy could conceivably serve to activate these preexperimental associations and thereby be highly effective (Rohwer, 1980). On the other hand, a word list composed of words not so routinely categorized could be better learned with a categorization strategy than with a strategy focusing on elaboration of individual items (Einstein \& Hunt, 1980).

Finally, the present findings support an approach to learning-strategies training that involves instruction on a variety of cognitive strategies (e.g., Weinstein et al., 1979). Some of these learning-strategies training programs have met with little success (Schmeck, 1983; Weinstein, 1978), however. Such programs have trained students in the use of learning strategies drawn in part from theory and research based on traditional laboratory learning tasks. The limited success of these programs might be understood in terms of the task-appropriateprocessing framework. Learning strategies developed from basic research using laboratory materials and tasks may not optimally enhance performance for material typically learned in the classroom. Rather, a more successful training program appears to depend on a more detailed analysis of the task and material so that an appropriate match between processing strategy and learning task can be ensured. Consistent with this position is the finding that a learning-strategies training program developed on the basis of a detailed analysis of the learning task of interest (in this case, reading) enhanced performance up to 1 year after the training program (Brown, Campione, \& Day, 1981).

Another implication of this study for learning. strategies training has to do with the implicit assumption that learning-strategies training is indicated for "poor" learners, but not necessarily for "good"' learners. In both experiments, correlations of recall across learning tasks were nonsignificant for the "uninstructed" subjects. This suggests that learners do not necessarily fit into skill categories that generalize across all tasks. Such a finding is supportive of Pressley, Heisel, McCormick, and Nakamura's (1982) suggestion that interventionists need to 'make more fine-grained assessments than just 'good' 
and 'poor" " (p. 145). In the present study, a student with effective strategies for one or two kinds of material did not necessarily possess an effective strategy for a third kind of material. Learning-strategy training, therefore, might be more effective with an individual training approach: Strategy instruction would be administered to each student only for the learning tasks on which he or she is deficient.

\section{REFERENCES}

Aldridge, J. W., \& Crisp, T. (1982). Maintenance rehearsal and long-term recall with a minimal number of items. American Journal of Psychology, 95, 565-570.

Ambler, B., \& Maples, W. (1977). Role of rehearsal in encoding and organization for free recall. Journal of Experimental Psychology: Human Learning and Memory, 3, 295-304.

BADDEley, A. D. (1976). The psychology of memory. New York: Basic Books.

Baddeley, A. D. (1978). The trouble with levels: A reexamination of Craik and Lockhart's framework for memory research. Psychological Review, 85, 139-152.

Barclay, C. R. (1979). The executive control of mnemonic activity. Journal of Experimental Child Psychology, 27, 262-276.

BatTIG, W. F. (1975). Within-individual differences in "cognitive" processes. In R. L. Solso (Ed.), Information processing and Cognition: The Loyola Symposium. Hillsdale, NJ: Erlbaum.

Battig, W. F., \& Bellezza, F. S. (1979). Organization and and structure. New York: Academic Press.

Brown, A. L., Campione, J. C., \& Day, J. D. (1981). Learning to learn: On training students to learn from text. Educational Researcher, 10, 14-21.

Brown, A. L., \& Smiley, S. S. (1978). The development of strategies for studying prose passages. Child Development, 49, 1076-1088.

Craik, F. I. M., \& Lockhart, R. S. (1972). Levels of processing: A framework for memory research. Journal of Verbal Learning and Verbal Behavior, 11, 671-684.

Craik, F. I. M., \& Tulving, E. (1975). Depth of processing and the retention of words in episodic memory. Journal of Experimental Psychology: General, 104, 268-294.

Eingtein, G. O., \& Hunt, R. R. (1980). Levels of processing and organization: Additive effects of individual item and relational processing. Journal of Experimental Psychology: $\mathrm{Hu}$ man Learning and Memory, 6, 588-598.

Einstein, G. O., McDaniel, M. A., \& Battig, W. F. (1978, April). Making processing tasks more unique. Paper presented at the meeting of the Rocky Mountain Psychological Association, Denver.

GIPE, J. (1981, April). Investigation of techniques for teaching new word meanings. Paper presented at the meeting of the American Educational Research Association, Los Angeles.

Hunt, R. R., \& Einstein, G. O. (1981). Relational and itemspecific information in memory. Journal of Verbal Learning and Verbal Behavior, 20, 497-514.

JENKINs, J. J. (1974). Can we have a theory of meaningful memory? In R. L. Solso (Ed.), Theories in Cognitive Psychology: The Loyola Symposium. Potomac, MD: Erlbaum.

JENKINS, J. J. (1979). Four points to remember: A tetrahedral model of memory experiments. In L. S. Cermak \& F. I. M. Craik (Eds.), Levels of processing in human memory, Hillsdale, NJ: Erlbaum.

KaIL, R. V., JR., \& Siegel, A. W. (1977). The development of mnemonic encoding in children: From perception to abstraction. In R. V. Kail, Jr., \& J. W. Hagen (Eds.), Perspectives on the development of memory and cognition. Hillsdale, $\mathrm{NJ}$ : Erlbaum.

Kendall, C. R., Borkowski, J. G., \& Cavanaugh, J. C.
(1980). Metamemory and the transfer of an integrative strategy by EMR children. Intelligence, 4, 255-270.

MazURYK, G. F., \& Lockhart, R. S. (1974). Negative recency and levels of processing in free recall. Canadian Journal of Psychology, 28, 114-123.

McDaniel, M. A., Friedman, A., \& Bourne, L. E., Jr. (1978). Remembering the levels of information in words. Memory \& Cognition, 6, 156-164.

McDaniel, M. A., \& Masson, M. E. (1977). Long-term retention: When incidental semantic processing fails. Journal of $E x$ perimental Psychology: Human Learning and Memory, 3, 270-281.

McDaniel, M. A., \& Pressley, M. (in press). Putting the keyword method in context. Journal of Educational Psychology.

Montague, W. E. (1972). Elaborative strategies in verbal learning and memory. In G. H. Bower (Ed.), The psychology of learning and motivation (Vol. 6). New York: Academic Press.

Morris, C. D., Bransford, J. D., \& Franks, J. J. (1977). Levels of processing versus transfer appropriate processing. Journal of Verbal Learning and Verbal Behavior, 16, 519-533.

Norman, D. A. (1978). Notes toward a theory of complex learning. In A. M. Lesgold, J. W. Pellegrino, S. D. Fekkema, \& R. Glaser (Eds.), Cognitive psychology and instruction. New York: Plenum Press.

Paivio, A., Yuille, J. C., \& Madigan, S. A. (1968). Concreteness, imagery, and meaningfulness values for 925 nouns. Journal of Experimental Psychology Monographs, 76(1, Pt. 2).

Palincsar, A. S., \& Brown, A. L. (in press). Reciprocal teaching of comprehension-monitoring activities. Cognition and Instruction.

Pressley, M. (1982). Elaboration and memory development. Child Development, 53, 296-309.

Pressley, M., Borkowski, J. G., \& O'Sullivan, J. (in press). Memory strategy instruction is made of this: Metamemory and durable strategy use. Educational Psychologist.

Pressley, M., Heisel, B. E., McCormick, C. B., \& NakAmurA, G. V. (1982). Memory strategy instruction with children. In C. J. Brainerd \& Pressley (Eds.), Progress in cognitive development: Vol. 2. Verbal processes in children. New York: Springer-Verlag.

Pressiey, M., \& Levin, J. R. (1977). Developmental differences in subjects' associative learning strategies and performances: Assessing a hypothesis. Journal of Experimental Child Psy. chology, 24, 431-439.

Pressley, M., Levin, J. R., \& Bryant, S. L. (1982). Memory strategy instruction during adolescence: When is explicit instruction needed? In M. Pressley \& J. R. Levin (Eds.), Cognitive strategy research: Psychological foundations. New York: Springer-Verlag.

Pressley, M., Levin, J. R., Kuiper, N. A., Bryant, S. L., \& Michener, S. (1982). Mnemonic versus nonmnemonic vocabulary-learning strategies: Additional comparisons. Journal of Educational Psychology, 74, 693-707.

Pressley, M., Levin, J. R., \& Miller, G. E. (1982). The keyword method compared to alternative vocabulary-learning strategies. Contemporary Educational Psychology, 7, 50-60.

Roenker, D. L., Thompson, C. P., \& Brown, S. C. (1971). Comparison of measures for the estimation of clustering in free recall. Psychological Bulletin, 76, 45-48.

ROHWER, W. D., JR. (1980). An elaborative conception of learner differences. In R. E. Snow, P. A. Frederico, \& W. E. Montague (Eds.), Aptitude, learning, and instruction. Hillsdale, NJ: Erlbaum.

Rohwer, W. D., Jr., \& Bean, J. P. (1973). Sentence effects and noun-pair learning: A developmental interaction during adolescence. Journal of Experimental Child Psychology, 15, $521-533$.

ScHMEck, R. R. (1983). Learning styles of college students. In R. Dillon \& R. R. Schmeck (Eds.), Individual differences in cognition. New York: Academic Press.

Shaughnessy, J. J. (1981). Memory monitoring accuracy and 
modification of rehearsal strategies. Journal of Verbal Learning and Verbal Behavior, 20, 216-230.

STOFF, D. M., \& EAGLE, M. N. (1971). The relationship among reported strategies, presentation rate, and verbal ability and their effects on free recall learning. Journal of Experimental Psychology, 87, 423-428.

WEINSTE IN, C. E. (1978). Elaboration skills as a learning strategy. In H. F. O'Neil, Jr. (Ed.), Learning strategies. New York: Academic Press.

Weingtein, C. E., Underwood, V. L., Wicker, F. W., \& Cubbealy, W. E. (1979). Cognitive learning strategies; Visual and verbal elaboration. In H. F. O'Neil, Jr., \& C. D. Spielberger (Eds.), Cognitive and affective learning strategies. New York: Academic Press.

Wollen, K. A., Weber, A., \& Lowry, D. H. (1972). Bizarteness versus interaction of mental images as determinants of learning. Cognitive Psychology, 2, 518-523.

\section{NOTES}

1. We thank Claire Weinstein for providing us with a copy of the Learning Activities Questionnaire

2. In the instructed groups, very few subjects responded to the open-ended question (no subjects in the "imagery" group; one subject in the "sentence" group for the vocabulary and word-list tasks; two subjects in the "category" group-both for the vocabulary task and one each for the word-list and pairedassociate tasks). For the "uninstructed" group, six subjects responded to the open-ended question for one of the three tasks.

3. For some subjects, no strategy received a " 5 ." For these subjects, all strategies receiving a "4" were recorded.

4. One subject in the "appropriate" group responded to the open-ended question on the vocabulary task, and one subject in the "uninstructed" group responded on the paired-associate task.

(Manuscript received May 3, 1983 ;

revision accepted for publication February 24, 1984.) 